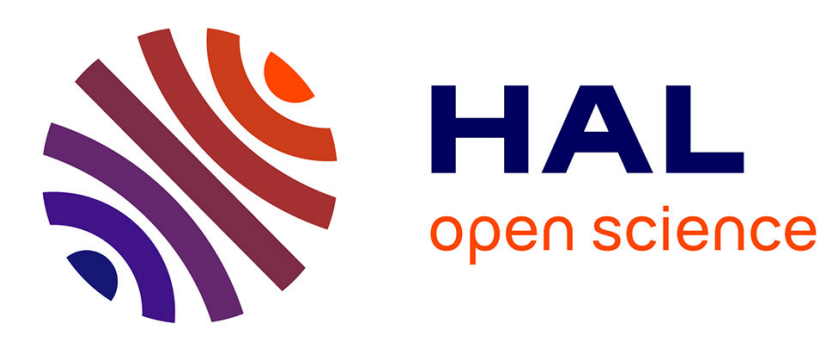

\title{
Reactive diffusion in the presence of a diffusion barrier: experiment and model
}

Dominique Mangelinck, T Luo, Christophe Girardeaux

\section{To cite this version:}

Dominique Mangelinck, T Luo, Christophe Girardeaux. Reactive diffusion in the presence of a diffusion barrier: experiment and model. Journal of Applied Physics, 2018, 123 (18), pp.185301. 10.1063/1.5023578 . hal-01790347

\section{HAL Id: hal-01790347 \\ https://hal.science/hal-01790347}

Submitted on 12 May 2018

HAL is a multi-disciplinary open access archive for the deposit and dissemination of scientific research documents, whether they are published or not. The documents may come from teaching and research institutions in France or abroad, or from public or private research centers.
L'archive ouverte pluridisciplinaire HAL, est destinée au dépôt et à la diffusion de documents scientifiques de niveau recherche, publiés ou non, émanant des établissements d'enseignement et de recherche français ou étrangers, des laboratoires publics ou privés. 


\title{
This manuscript was accepted by J. Appl. Phys. Click here to see the version of record.
}

\section{Reactive diffusion in the presence of a diffusion barrier: experiment and model}

\author{
D. Mangelinck, T. Luo, C. Girardeaux
}

IM2NP, CNRS, Aix Marseille Université, service 142, Faculté de saint Jérôme, 13397 Marseille,

France

Corresponding author: dominique.mangelinck@im2np.fr

\section{Abstract}

Reactions in thin film and diffusion barriers are important for applications such as protective coatings, electrical contact and interconnections. In this work the effect of a barrier on the kinetics of the formation for a single phase by reactive diffusion is investigated from both experimental and modeling point of view. Two types of diffusion barriers are studied: (i) a thin layer of $\mathrm{W}$ deposited between a Ni film and the Si substrate and (ii) $\mathrm{Ni}$ alloy films, $\mathrm{Ni}(1 \% \mathrm{~W})$ and $\mathrm{Ni}(5 \% \mathrm{Pt})$, that form a diffusion barrier during the reaction with the Si substrate. The effect of the barriers on the kinetics of $\delta-\mathrm{Ni}_{2} \mathrm{Si}$ formation is determined by in situ $\mathrm{X}$ ray diffraction and compared to models that explain the kinetics slowdown induced by both types of barrier. A linear parabolic growth is found for the deposited barrier with an increasing linear contribution for increasing barrier thickness. On the contrary, the growth is mainly parabolic for the barrier formed by reaction between an alloy film and the substrate. The permeability of the two types of barrier are determined and discussed. The developed models fit well with the dedicated model experiments, leading to a better understanding of the barrier effect on the reactive diffusion and allowing to predict the barrier behaviour in various applications.

\section{Keywords}

Diffusion barrier; reactive diffusion; model; growth kinetics; Nickel silicide 


\section{Introduction}

Thin film reactions and diffusion barriers are of interest in numerous applications of protective coatings in metallurgy, intermetallic control in aeronautics, interlayer in diffusion welding, and contact formation and interconnections in microelectronics.

In metallurgy, a diffusion barrier is a thin layer of metal usually placed between two other metals in order to protect either one of the metals from modifying the other [1]. In aeronautics, the diffusion barrier may come from the segregation of a impurities contained in one of the materials and it could limit the growth of intermetallic [2] [3].

In microelectronics, barriers are usually introduced to chemically isolate semiconductors from metal interconnects, while maintaining an electrical connection between them. For instance, a layer of barrier metal must surround every copper interconnection in modern copper-based chips, to prevent diffusion of copper into surrounding materials [4] [5].

In most of these cases, the growth of phases such as intermetallics occurs and reactive diffusion is involved. This is also the case in thin film reactions in which both diffusion and reaction are contributory. Driven by the applications, a considerable amount of work has been done on reactive diffusion both from the experimental [6][7] [8] and theoretical aspect [9] [10] [11] [12] [13] [14]. In microelectronics, the formation of contact in devices is obtained by reaction between of a metal film and the Si substrate to form a silicide. The formation of these silicide films has been largely studied for thickness in the range of a few hundreds of nanometers [6][7] and more recently for smaller thickness [15] [16]. These studies on silicide and other studies on different systems [17] [18] have shown that the reactions in thin films (typically between 20 and $200 \mathrm{~nm}$ ) [5] are usually characterized by a sequential growth, the absence of some equilibrium phases, and sometimes by the growth of metastable phases, while the simultaneous parabolic growth of all the equilibrium phases is usually observed in bulk interdiffusion couples. It was also shown that after the nucleation and the lateral growth that leads to a continuous layer, the thickening of the layer will occur by linear-parabolic growth [16]. This model of growth was first stated by Evans [19] and then demonstrated by Deal and Grove [20] in the case of silicon oxidation. The growth of a single compound layer combine two types of process: (i) the rearrangement of the atoms at the interfaces required for the growth of the compound layer which may involve a reaction barrier and (ii) 
the diffusion of matter across the compound layer in which the diffusion flux slows down with increasing the layer thickness. If the interfacial reaction barriers control the kinetics, it is termed interface controlled (or reaction controlled) and the layer thickness increases linearly with time. If the diffusion process is rate limiting and controls the growth, the corresponding kinetics is termed diffusion controlled and the layer thickness increases proportional to the square root of time. Since the early works [19] [20], several studies deals with the linear parabolic growth as well as with its implication for the sequential growth both from experimental [21] [22] [23] or theoretical [24] [25] [26] point of view.

The Ni thin film reaction with silicon can be considered as a characteristic system for reactive diffusion and presents a large interest for application. Most of the studies on the reaction between a pure Ni thin film and the Si substrate have shown the following sequence of phases during the reaction [27]: $\delta-\mathrm{Ni}_{2} \mathrm{Si}$ appears as the first phase and grows at low temperature (from $250^{\circ} \mathrm{C}$ ) until full consumption of the $\mathrm{Ni}$ metallic film. The NiSi phase then grows at the expense of the $\delta-\mathrm{Ni}_{2} \mathrm{Si}$ phase and is stable in a temperature range up to $700-800^{\circ} \mathrm{C}$. The third phase $\mathrm{NiSi}_{2}$ grows after $\mathrm{NiSi}$ at a temperature normally higher than $700^{\circ} \mathrm{C}$ since it has difficulty in nucleation [28]. With the downscaling of microelectronic devices, $\mathrm{NiSi}$ is widely used as contacts in complementary-metal-oxide-semiconductor (CMOS) transistors because of its low resistivity, low Si consumption and Ni diffusion controlled reaction [29]. However, its application is limited by the agglomeration of NiSi and the formation of the high resistivity $\mathrm{NiSi}_{2}$ at intermediate temperature $\left(500^{\circ} \mathrm{C} \sim 800^{\circ} \mathrm{C}\right)$ that leads to a degradation of the contact resistance. In order to solve these issues, $\mathrm{Ni}$ has been alloyed with different elements to increase the stability of NiSi.[30] [31] [32], Mangelinck et al. [30] [31][31] have shown that the additive 5 at. \% Pt in the Ni film can increase the temperature of $\mathrm{NiSi}_{2}$ nucleation and delay the agglomeration of $\mathrm{NiSi}$ by more than $100^{\circ} \mathrm{C}$. Lavoie et al. [32] have systematically investigated the role of alloy on the stability of NiSi: the additions of $\mathrm{Pt}, \mathrm{Pd}$ and $\mathrm{Rh}$ are most efficient to delay the formation of $\mathrm{NiSi}_{2}$ while elements such as $\mathrm{W}$, Mo, Re, and Ta are amongst the most efficient elements to delay the NiSi agglomeration. Adding alloying element of Pt or W to Ni film could also significantly modify the Ni silicides formation at low temperature [34] [35] [36] [37] . However a clear understanding of this effect is still not fully achieved [15]. A common way to introduce an alloy element is to place a thin metal layer (interlayer) between the $\mathrm{Ni}$ film and the Si substrate instead to deposit an alloy [38] [39] [40] [41]: this was shown to change the stability of the $\mathrm{Ni}$ silicide as well as their formation. The presence of a thin $\mathrm{SiO}_{2}$ layer can also modify greatly the 

[43].

The goal of this work is to investigate the effect of a diffusion barrier or an interlayer on the reactive diffusion and more precisely on the kinetics of formation of a single phase by reactive diffusion. The kinetics of the $\delta-\mathrm{Ni}_{2} \mathrm{Si}$ phase formation has been measured by in situ $\mathrm{X}$ ray diffraction during isothermal annealing of pure $\mathrm{Ni}$ film, $\mathrm{Ni}$ film with a $\mathrm{W}$ barrier, and $\mathrm{Ni}(5 \% \mathrm{Pt})$ films. Two models are developed to explain the change in kinetics in the presence of a deposited barrier or of a diffusion barrier that is built during the consumption of an alloy. A comparison between the model and the experimental result allows to validate the two models and to obtain experiment values for the permeability of the barrier which is the product of the diffusion coefficient and the atomic fraction of the diffusing species in the barrier. These models should allow to design a barrier or an interlayer in a variety of applications.

\section{Experimental procedure}

Three types of samples were deposited on $\mathrm{Si}(100)$ at room temperature by magnetron sputtering system using $\mathrm{Ni}, \mathrm{W}$, and $\mathrm{Ni}(5 a t . \% \mathrm{Pt})$ targets. Note that, in the following, the atomic fraction are given in at. $\%$ but will be expressed as $\%$ to simplify the notation. The Si substrate was immersed into a $5 \%$ dilute HF solution for $1 \mathrm{~min}$ to remove the native oxide prior loading into the sputtering chamber. The deposition was performed with a base pressure of $\sim 10^{-8}$ Torr using $99.9999 \%$ pure Ar gas flow. The two first types of samples are $50 \mathrm{~nm}$ thick pure Ni films deposited either directly on the Si substrate or on a W barrier with two thicknesses ( 0.5 or $1 \mathrm{~nm})$. The third type of samples consists of $50 \mathrm{~nm}$ thick $\mathrm{Ni}$ alloys, $\mathrm{Ni}(1 \% \mathrm{~W})$ and $\mathrm{Ni}(5 \% \mathrm{Pt})$, on $\mathrm{Si}(100)$. The $\mathrm{Ni}(1 \% \mathrm{~W})$ film was obtained by co sputtering of the $\mathrm{Ni}$ and $\mathrm{W}$ targets while the $\mathrm{Ni}(5 \% \mathrm{Pt})$ was deposited from the $\mathrm{Ni}(5 \% \mathrm{Pt})$ target. In order to avoid oxidation during the heat treatment, a $20 \mathrm{~nm}$ thick $\mathrm{SiO}_{2}$ layer was deposited by low pressure chemical vapor deposition on top of all the samples.

In-situ XRD measurements were performed using a Cu Ka source, a rapid detector (PANalytical PIXcel) and a chamber equipped with a heating stage under a vacuum of $\sim 10^{-5}$ mbar. During the in situ XRD measurement, the temperature was increased from room temperature to $270{ }^{\circ} \mathrm{C}$ at a rate of $35^{\circ} \mathrm{C} / \mathrm{min}$ and 4.6 min long XRD scans were then recorded continuously during various time at this temperature. The XRD peak were then fitted using a pseudo-Voigt function in order to extract the variation of the XRD peak intensity as a function of the time. 
This manuscript was accepted by J. Appl. Phys. Click here to see the version of record.

\section{Results}

Figure 1 shows the XRD intensity as a function of the 2 theta angle and the time for (a) $50 \mathrm{~nm} \mathrm{Ni}$, (b) $50 \mathrm{~nm} \mathrm{Ni} / 0.5 \mathrm{~nm} \mathrm{~W}$, (c) $50 \mathrm{~nm} \mathrm{Ni} / 1 \mathrm{~nm} \mathrm{~W}$, and (d) Ni(5\%)Pt films on Si(100) during the in situ annealing at $270^{\circ} \mathrm{C}$. The in situ $\mathrm{XRD}$ measurement for the $\mathrm{Ni}(1 \% \mathrm{~W})$ samples is not presented here but they are intermediate between the one of pure $\mathrm{Ni}$ and the one of $\mathrm{Ni}(10 \% \mathrm{Pt})$. In all cases, the $\delta-\mathrm{Ni}_{2} \mathrm{Si}$ phase is growing at the extent of the metal film $(\mathrm{Ni}, \mathrm{Ni}(1 \% \mathrm{~W})$, or $\mathrm{Ni}(5 \% \mathrm{Pt}))$. When the metal film has been consumed, NiSi grows (this can only be seen in Fig. 1.b but it has been also observed for the other cases in other in situ XRD experiments not shown here). Note that the time scale is not the same for all the measurements and that the time to complete the formation of $\delta-\mathrm{Ni}_{2} \mathrm{Si}$ is largely increased in the case of the presence of a barrier or the alloy metal film. The difference in texture for the samples without deposited barrier $(50 \mathrm{~nm} \mathrm{Ni}, 50 \mathrm{~nm} \mathrm{Ni}(1 \% \mathrm{~W})$ and $\mathrm{Ni}(5 \% \mathrm{Pt})$ films) and with deposited barrier $(50 \mathrm{~nm} \mathrm{Ni}$ / $0.5 \mathrm{~nm} \mathrm{~W}, 50 \mathrm{~nm} \mathrm{Ni} / 1 \mathrm{~nm} \mathrm{~W}$ ) may be due to difference in alloying element concentration, intermixed layer...

In order to compare the kinetics of $\delta-\mathrm{Ni}_{2} \mathrm{Si}$, the intensity of the XRD peaks obtained by fitting with a pseudo Voight function are reported as a function of time in Fig. 2. As the XRD intensity is proportional to the volume of the phase and as the texture is not changing noticeably during the isothermal heat treatment (Fig. 1), the intensity can be used as an estimate of the thickness of $\delta$ - $\mathrm{Ni}_{2} \mathrm{Si}$. The XRD peak intensity was thus converted into thickness by normalisation and multiplication by the thickness of $\delta$ $\mathrm{Ni}_{2} \mathrm{Si}$ expected from the atomic volume change for $50 \mathrm{~nm}$ of $\mathrm{Ni}$ (i.e. $\sim 75 \mathrm{~nm}$ ) [7]. Figure 2.a shows the $\delta$ $\mathrm{Ni}_{2} \mathrm{Si}$ thickness as a function of time and confirms that the $\mathrm{W}$ barrier or the presence of $\mathrm{Pt}$ in the $\mathrm{Ni}$ film delays to a large extent the formation of $\delta-\mathrm{Ni}_{2} \mathrm{Si}$. Moreover the log-log plot in Fig. 2.b indicates that the variation of the thickness with time show a different behaviour for the samples with $\mathrm{W}$ barrier than for the pure $\mathrm{Ni}, \mathrm{Ni}(1 \% \mathrm{~W})$, and $\mathrm{Ni}(5 \% \mathrm{Pt})$ samples. Indeed the pure $\mathrm{Ni}, \mathrm{Ni}(1 \% \mathrm{~W})$, and $\mathrm{Ni}(5 \% \mathrm{Pt})$ samples show a parabolic growth as indicated by the $t^{1 / 2}$ slope while the barrier samples have a more complex behaviour close to a linear variation.

\section{Modelling of the barrier effect on reactive diffusion for a single phase}

In order to better understand the experimental results, two models for the kinetics of formation in the presence of a barrier are now developed. 


\section{This manuscript was accepted by J. Appl. Phys. Click here to see the version of record.}

We will consider the following situation illustrated in Fig. 3: an intermetallic compounds, $\delta=A_{p} B_{q}$, is growing by diffusion between two ends phases, $\alpha$ and $\gamma$, in the presence of a barrier, $\beta$, located between $\alpha$ and $\delta$. The $\alpha$ phase is either a pure element or an alloy $A_{1-x} B_{x}$. Moreover we will consider that atom $A$ is the main diffusing specie and that the diffusion of $B$ is negligible in all the phases. We will further assume that the diffusion of $A$ in the ends phases is negligible. These assumptions allow to simplify greatly the equations. The first assumption is valid for $\delta-\mathrm{Ni}_{2} \mathrm{Si}$ in which Ni diffuses much faster that $\mathrm{Si}$. The diffusion of $\mathrm{Ni}$ in $\mathrm{Si}$ is fast but its solubility is very low in $\mathrm{Si}$. The flux of $\mathrm{Ni}$ in $\mathrm{Si}$ can thus be consider as negligible compared to the ones in the barrier and in $\delta$ - $\mathrm{Ni}_{2} \mathrm{Si}$ validating the second assumption.

In these conditions, the growth rate of the $\delta$ phase is related to the flux of A atoms in the $\delta$ phase, $J_{A}^{\delta}$ , by the following relationship:

$$
\left\langle\frac{d L^{\delta}}{d t}=\Omega_{\delta / \gamma}^{\delta} J_{A}^{\delta}\right.
$$

where $L^{\delta}$ and $J_{A}^{\delta}$ are the thickness of $\delta$ and the flux of A through $\delta . \Omega_{\delta / \gamma}^{\delta}$ is the volume of $\delta$ formed by atom of the mobile species ( $\mathrm{A}$ in this case) at the growing interface.

Since the reaction at the $\delta / \gamma$ interface is:

$$
A(\delta)+\frac{q}{p} B \Rightarrow \frac{1}{p} A_{p} B_{q}
$$

the volume of $\delta$ formed by atom of the mobile species is:

$$
\Omega_{\delta / x}^{\delta}=\frac{1}{p} \Omega^{\delta}=\frac{p+q}{p} \omega^{\delta}=\frac{\omega^{\delta}}{x_{A}^{\delta}}=\frac{1}{c_{A}^{\delta}}
$$

$\Omega^{\delta}, \omega^{\delta}, x_{A}^{\delta}$, and $c_{A}^{\delta}$ are, respectively, the volume occupied by a formula unit, the atomic volume, the atomic fraction and the concentration of the diffusing species. 


$$
\frac{d L^{\delta}}{d t}=\Omega_{\delta / \gamma}^{\delta} J_{A}^{\delta}=\frac{1}{c_{A}^{\delta}} J_{A}^{\delta}
$$

As many intermetallic compounds exist only within very narrow limits of composition, and, when this is not precisely true, within poorly known limits of composition, growth kinetics cannot be properly interpreted in terms of Fick's law. It is thus more appropriated to consider diffusion in terms of the modified Nernst-Einstein equation:

$$
J_{A}^{\delta}=-c_{A}^{\delta}\left(\frac{D_{A}^{\delta}}{R T}\right) \frac{\partial \mu_{A}^{\delta}}{\partial \mathbf{z}}
$$

where the flux of $A$ atoms, $J_{A}$, is expressed as the product of the concentration of $A$ atoms $\left(c_{A}^{\delta}\right)$, their mobility, $\frac{D_{A}^{\delta}}{R T}$, and the gradient of chemical potential (i.e. the force on these atoms), $\frac{\partial \mu_{A}^{\delta}}{\partial z}$.

Furthermore, $\frac{\partial \mu_{A}^{\delta}}{\partial \mathbf{z}}$, the gradient of chemical potential is taken equal to $\frac{\Delta \mu_{A}^{\delta}}{L^{\alpha}}$ with $\Delta \mu_{A}^{\delta}$, the chemical potential change per moving $A$ atom [44]:

$$
\mathrm{J}_{A}^{\delta}=-c_{A}^{\delta}\left(\frac{D_{A}^{\delta}}{R T}\right) \frac{\Delta \mu_{A}^{\delta}}{L^{\delta}}
$$

Moreover, the use of the gradient of chemical potential would require complete knowledge of the free energies versus composition for the whole A/B system, and would become meaningful only if it was possible to determine the varying value of $D_{A}$ as a function of the chemical potential of $A$ within the compound.

Similarly the flux trough the barrier is expressed as :

$$
J_{A}^{\beta}=-C_{A}^{\beta}\left(\frac{D_{A}^{\beta}}{R T}\right) \frac{\Delta \mu_{A}^{\beta}}{L^{\beta}}
$$

where $\Delta \mu_{A}^{\delta}=\mu_{3}-\mu_{2}$ and $\Delta \mu_{A}^{\beta}=\mu_{2}-\mu_{1}$ 


\section{This manuscript was accepted by J. Appl. Phys. Click here to see the version of record.}

Assuming a steady state of the diffusion flux $\left(J_{A}^{\delta}=J_{A}^{\beta}\right)$ and equilibrium at the interfaces (equality of the chemical potential), one obtains the following expression:

$$
J_{A}^{\delta}=J_{A}^{\beta} \Leftrightarrow \mu_{2}=\frac{\varphi^{\delta} \mu_{3}+\varphi^{\beta} \mu_{1}}{\varphi^{\delta}+\varphi^{\beta}}
$$

Eq. 6

where $\varphi^{\delta}=\frac{{ }_{c_{A}^{\delta} D_{A}^{\delta}}}{L^{\delta}}$ and $\varphi^{\beta}=\frac{{ }_{{ }_{A}^{\beta}}^{\beta} D_{A}^{\beta}}{L^{\beta}}$

$$
\frac{d L^{\delta}}{d t}=\frac{1}{\left(1 / \varphi^{\delta}+1 / \varphi^{\beta}\right)} \frac{\left(\mu_{1}-\mu_{3}\right)}{c_{A}^{\delta} R T}=\left(\frac{L^{\delta}}{D_{A}^{\delta}}+\frac{c_{A}^{\delta} L^{\beta}}{c_{A}^{\beta} D_{A}^{\beta}}\right)^{-1} \frac{\left(\mu_{1}-\mu_{3}\right)}{R T}
$$

If the ends phases are the pure elements, the variation of the chemical potential can be related to the Gibbs energy of formation of the phase per mole of atoms, $\Delta G\left(A_{p} B_{q}\right)=\Delta G^{\delta}$ by $\mu_{1}-\mu_{3}=\frac{p+q}{p} \Delta G^{\delta}$

\subsection{Fixed thickness and fixed concentration for the barrier}

The barrier may have a fixed thickness and a fixed concentration in several cases: for examples, when a layer is deposited between $A$ and $B$ or when a thin oxide layer is present at the $A / B$ interface. In this case, $L^{\beta}, c_{A}^{\delta}$, and $D_{A}^{\beta}$ are independent of time and Eq. 7 can be simplified to

$$
\frac{d L^{\delta}}{d t}=\left(\frac{L^{\delta}}{D_{A}^{\delta}}+\frac{1}{\mathrm{~K}}\right)^{-1} \frac{\left(\mu_{1}-\mu_{3}\right)}{R T}
$$

where $\mathrm{K}=\frac{c_{A}^{\beta} D_{A}^{\beta}}{c_{A}^{\delta} L^{\beta}}$. 
Equation 8 is formally equivalent to the Deal and Groove law [20]. For isothermal heat treatment, Eq. 8 can be integrated to obtain a linear parabolic equation for the growth of the $\delta$ phase.

The parameter $\mathrm{K}$ depends mainly on two factors: the thickness of the barrier and its permeability defined as the product of the concentration and diffusion coefficient of $\mathrm{A}$ in the barrier: $P_{A}^{\beta}=x_{A}^{\beta} D_{A}^{\beta}$.

In order to reduce the number of parameters, the permeability will be used in the following instead of the concentration and diffusion coefficient of $A$ in the barrier.

Figure 4.a show the variation of the thickness as a function of time for different thickness. The following typical values were taken for this figure and will be used also in the next paragraph: $\left(\mu_{1}-\mu_{3}\right) / R T=15$ , $\omega^{\delta}=\omega^{\beta}=0.01 \mathrm{~nm}^{3} /$ at.,$c_{A}^{\delta}=2 / 3$, and $D_{A}^{\delta}=1 \mathrm{~nm}^{2} / \mathrm{s}$.

Figure 4.a shows that the more the barrier is efficient to delay the diffusion, the more the growth kinetics is slowed down and the more it becomes linear. This is further more illustrated in Fig. 4.b where the $\mathrm{K}$ factor (Eq. 8) is plotted as a function of the barrier thickness. Note that the permeability and barrier thickness have an inverse role on the kinetics (Eq. 8): decreasing permeability leads thus to a very similar behavior than increasing barrier thickness.

\subsection{Formation of one phase for a barrier built by consumption of an alloy}

When the phase is formed from an alloy, $\alpha=A_{1-x_{0}} C_{x_{0}}$, the $C$ element can be not incorporated in the forming phase and accumulates at the $\alpha / \delta$ interface. As a first approximation, this case can be modelled as a barrier with a fixed concentration, $x^{\beta}$, i.e. $\beta=A_{1-x^{\beta}} C_{x^{\beta}}$, and a thickness that increases when the thickness of the $\delta$ phase increases. If the amount of $\mathrm{C}$ in the $\delta$ phase is negligible, the thickness of the barrier is then given by the conservation of matter:

$$
L^{\beta}=\frac{c_{A}^{\delta} c_{C}^{\alpha}}{c_{A}^{\alpha} c_{C}^{\beta}-c_{A}^{\beta} c_{C}^{\alpha}} L^{\delta}
$$




\section{This manuscript was accepted by J. Appl. Phys. Click here to see the version of record.}

Taking Eq. 7 and 9, the growth rate is given by

$$
\frac{d L^{\delta}}{d t}=\frac{c_{A}^{\delta}}{L^{\delta}}\left(\frac{1}{D_{A}^{\delta}}+\frac{c_{C}^{\alpha}\left(c_{A}^{\delta}\right)^{2}}{c_{A}^{\beta}\left(c_{A}^{\alpha} c_{C}^{\beta}-c_{A}^{\beta} c_{C}^{\alpha}\right)} \frac{1}{D_{A}^{\beta}}\right)^{-1} \frac{\left(\mu_{1}-\mu_{3}\right)}{R T c_{A}^{\delta}}
$$

Since all the parameter in the parenthesis of Eq. 10 do not depend on time, one obtains:

$$
\frac{d L^{\delta}}{d t}=\frac{D^{e f f}}{L^{\delta}} \frac{\left(\mu_{1}-\mu_{3}\right)}{R T}
$$

Eq. 11 shows that in the case of barrier coming from an alloy, the growth inversely proportional to the thickness of the growing phase and is proportional to an effective coefficient, $D^{\text {eff }}$ :

$$
D^{\text {eff }}=\frac{1}{\frac{1}{D_{A}^{\delta}}+\frac{\chi}{D_{A}^{\beta}}}=\frac{D_{A}^{\delta}}{1+\chi \frac{D_{A}^{\delta}}{D_{A}^{\beta}}}
$$

where $\chi=\frac{c_{C}^{\alpha}\left(c_{A}^{\delta}\right)^{2}}{c_{A}^{\beta}\left(c_{A}^{\alpha} c_{C}^{\beta}-c_{A}^{\beta} c_{C}^{\alpha}\right)}=\frac{\left(1-x_{A}^{\alpha}\right)\left(x_{A}^{\delta}\right)^{2}}{x_{A}^{\beta}\left(x_{A}^{\alpha}\left(1-x_{A}^{\beta}\right)-x_{A}^{\beta}\left(1-x_{A}^{\alpha}\right)\right)}\left(\frac{\omega^{\beta}}{\omega^{\delta}}\right)^{2}$

For isothermal heat treatment, the kinetics of formation will thus be parabolic.

Figure 5.a shows the kinetics of formation for the same parameter than the one used in Fig. 4. For an atomic fraction of 0.1 in the alloy and for different values of the barrier permeability: the kinetics is always parabolic but decreased with decreasing permeability. Figure 5.b shows also that the effective diffusion depends strongly on the atomic fraction of $\mathrm{C}$ in the alloy.

\section{Discussion}

In order to compare these models to experiments, the XRD in situ measurements have been fitted by Eq. 8 for the $\mathrm{Ni}$ film with or without $\mathrm{W}$ barrier and by Eq. 11 for the $\mathrm{Ni}$ alloy film, $\mathrm{Ni}(1$ at. $\% \mathrm{~W})$ and $\mathrm{Ni}(5$ at. $\%$ Pt). Figure 6 shows that the simulation reproduce well the experimental variation of $\delta-\mathrm{Ni}_{2} \mathrm{Si}$ thickness for the different sample. In the fitting procedure, the kinetics for the Ni film without $\mathrm{W}$ barrier was first used to determine the diffusion coefficient of $\mathrm{Ni}$ in $\delta-\mathrm{Ni}_{2} \mathrm{Si}\left(D_{A}^{\delta}=0.04 \mathrm{~nm}^{2} / \mathrm{s}\right)$. The permeability of the barrier was then adjusted to fit the variation of $\delta-\mathrm{Ni}_{2} \mathrm{Si}$ thickness for the samples with $\mathrm{W}$ barrier 


\section{This manuscript was accepted by J. Appl. Phys. Click here to see the version of record.}

(Eq. 8) and the NiPt sample (Eq. 11). The permeability for each sample are reported in table I and the following values were used: $T=270^{\circ} \mathrm{C}, \omega^{\delta}=\omega^{\beta}=0.01 \mathrm{~nm}^{3} /$ at.,$\Delta G^{\delta}=-45 \mathrm{~kJ} /$ at.gram .

Table 1 shows that the value of the permeability are relatively close to each other for the three samples. The similar value for the two samples with $\mathrm{W}$ barrier validates that the linear term, $\mathrm{K}$, in Eq. 8 is indeed inversely proportional to the barrier thickness. It appears that the permeability (i.e. the "weakness") of the barrier is similar for $\mathrm{W}$ and $\mathrm{Pt}$ which is coherent with former results concerning the formation of $\mathrm{Ni}$ silicide from $\mathrm{Ni}(\mathrm{Pt})$ and $\mathrm{Ni}(\mathrm{W})$ alloy where the growth behaviour of this phase were similar.

Table 1: Permeability obtained from the fit of the experimental kinetics. The following parameters were taken for the fit: $\left(\mu_{1}-\mu_{3}\right) / R T=15, \omega^{\delta}=\omega^{\beta}=0.01 \mathrm{~nm}^{3} /$ at.,$c_{A}^{\delta}=2 / 3$, and $D_{A}^{\delta}=1 \mathrm{~nm}^{2} / \mathrm{s}$.

Figure 6.d also shows that the simulation fits less well the experiment when the thickness of $\delta-\mathrm{Ni}_{2} \mathrm{Si}$ becomes large in the case of the $\mathrm{Ni}(\mathrm{Pt})$ film. This is certainly an indication of the limitation of the model for the alloy film. Indeed the assumption of a constant concentration and a constant diffusion coefficient 
is quite restrictive since the real situation may be more a gradient in the Pt concentration as indicated by APT measurement [45].

Note that Eq. 8 and 11 do not take into account the usual reaction barrier in the linear parabolic growth that account for the rearrangement of the atoms at the interfaces required for the growth of the compound layer [20]. This term can easily be included in these equations but should have a much lower impact on the kinetics that the barrier. The alloy element or the barrier element may also change the diffusion in the growing phase by segregating at the grain boundaries [46] and further work may be needed to separate the two effects. Grain growth in the barrier might also induce a change in the effective diffusion coefficient taking into account both inter and intra grain diffusion in the barrier.

The relatively small change in $\mathrm{P}$ for the two $\mathrm{W}$ barriers ( $30 \%$ difference) may be attributed to the intermixing that is usually observed when a metal film is deposited on Si. This intermixing has been observed to occur over on 1 or 2 nanometers for Ni. For a refractory metal such as $\mathrm{W}$, the intermixing may be more limited but could explain the $30 \%$ difference. Moreover a common assumption is that the grain size scales with the thickness of the layer. One could thus expect a difference in the grain size of the barrier layer. As diffusion is expected to occur via grain boundaries in the barrier, this change in grain size would also contribute to the measured $30 \%$ change in $\mathrm{P}$.

The models used in the simulation are based on the assumption of one-dimensional growth. However, nucleation at the interface and/or at the triple junction, as well as the lateral growth along interface play an important role in the formation of silicide. This is particularly true for very thin films [47] and may lead to much more complex microstructures. Anyway, for thickness larger than about $10 \mathrm{~nm}$, the nucleation and lateral growth end to a continuous layer which grows then essentially in a one-dimensional manner.

Nevertheless, even if the two models are simple, they allow to reproduce the experimental behaviour and in particular the difference in kinetics regime: linear-parabolic for a deposited barrier and parabolic for a barrier resulting from an alloy consumption. Furthermore the similarity between the permeability allows to validate the models. Further investigations are in progress to compare the permeability value for other alloy elements.

These models are the basis for a simulation method to interpret the barrier effect and they match well with our dedicated model experiments that can be much more difficult to analyze for more complex systems. They should enable to better understand and to predict the barrier behaviour both in 
by simple parameters such as the barrier permeability. Even if these parameters may depend on the barrier microstructure (for example grain size, grain structure, texture...), our first experiment shows that, for a given process (sputtering in our case), these parameters could be materials constants and our models may thus help to design and to process barriers or interlayers for applications in metallurgy, microelectronics, aeronautics...

\section{Conclusion}

The effect of a barrier on the kinetics of the formation for a single phase by reactive diffusion has been investigated from the experimental and modeling point of view. Two types of diffusion barrier have been studied: barrier deposited as a thin layer of $\mathrm{W}$ between a Ni film and the Si substrate or barrier built during the reaction between $\mathrm{Ni}$ alloy films, $\mathrm{Ni}(1 \% \mathrm{~W})$ or $\mathrm{Ni}(5 \% \mathrm{Pt})$, and $\mathrm{Si}$. The kinetics of $\delta-\mathrm{Ni} 2 \mathrm{Si}$ formation have been measured by in situ XRD measurement for the two type of barrier and compared to the one of pure Ni. Models have been developed for the two cases and fitted to experiments. The main conclusion are: (i) the two types of barrier decreases the rate of the $\delta-\mathrm{Ni}_{2} \mathrm{Si}$ phase formation (ii) the linear contribution in the linear parabolic growth becomes more important for increasing deposited barrier thickness while the growth is mainly parabolic for a barrier coming from an alloy (iii) the two model fit well the experiments (iv) the measured permeability are similar for different thickness of the barrier and for the two types of barrier. The developed models make it possible to design barriers or interlayers in a variety of applications.

\section{Acknowledgements}

The French ministry for education and research is acknowledged for providing the scholarship for the PhD of T. Luo. The authors would like to thank M. Descoins and M. Bertoglio for technical assistance.

\section{References}

[1] R.W. Cahn, P. Haasen, Physical Metallurgy, Elsevier, 1996. 
This manuscript was accepted by J. Appl. Phys. Click here to see the version of record.

[2] Z. Zhang, B. Bai, H. Peng, S. Gong, H. Guo, Effect of Ru on interdiffusion dynamics of $\beta$ NiAl/DD6 system: A combined experimental and first-principles studies, Mater. Des. 88 (2015) 667-674. doi:10.1016/j.matdes.2015.09.041.

[3] M. Bai, H. Jiang, Y. Chen, Y. Chen, C. Grovenor, X. Zhao, P. Xiao, Migration of sulphur in thermal barrier coatings during heat treatment, Mater. Des. 97 (2016) 364-371. doi:10.1016/j.matdes.2016.02.109.

[4] M.-A. Nicolet, Diffusion barriers in thin films, Thin Solid Films. 52 (1978) 415-443. doi:10.1016/0040-6090(78)90184-0.

[5] A. Kaloyeros, E. Eisenbraun, Ultrathin Diffusion Barriers Liners for Gigascale Copper Metallization, Annu. Rev. Mater. Sci. - ANNU REV MATER SCI. 30 (2000) 363-385. doi:10.1146/annurev.matsci.30.1.363.

[6] F.M. d'Heurle, P. Gas, Kinetics of formation of silicides; A review, J. Mater. Res. 1 (1986) 205221. doi:10.1557/JMR.1986.0205.

[7] M.-A. Nicolet, S.S. Lau, Chapter 6 - Formation and Characterization of Transition-Metal Silicides, in: N.G. Einspruch, G.B. Larrabee (Eds.), VLSI Electron. Microstruct. Sci., Elsevier, 1983: pp. 329-464. doi:10.1016/B978-0-12-234106-9.50011-8.

[8] E.G. Colgan, A review of thin-film aluminide formation, Mater. Sci. Rep. 5 (1990) 1-44. doi:10.1016/S0920-2307(05)80005-2.

[9] G.V. Kidson, Some aspects of the growth of diffusion layers in binary systems, J. Nucl. Mater. 3 (1961) 21-29. doi:10.1016/0022-3115(61)90175-1.

[10] J. Philibert, Atom Movements: Diffusion and Mass Transport in Solids, Editions de Physique, 1991.

[11] A. Borgenstam, L. Höglund, J. Agren, A. Engström, DICTRA, a tool for simulation of diffusional transformations in alloys, J. Phase Equilibria. 21 (2000) 269. doi:10.1361/105497100770340057.

[12] J. Svoboda, E. Gamsjäger, F.D. Fischer, P. Fratzl, Application of the thermodynamic extremal principle to the diffusional phase transformations, Acta Mater. 52 (2004) 959-967. doi:10.1016/j.actamat.2003.10.030.

[13] M. Kajihara, Analysis of kinetics of reactive diffusion in a hypothetical binary system, Acta Mater. 52 (2004) 1193-1200. doi:10.1016/j.actamat.2003.10.047.

[14] Z. Erdelyi, G. Schmitz, Reactive diffusion and stresses in spherical geometry, Acta Mater. 60 (2012) 1807-1817. doi:10.1016/j.actamat.2011.12.006.

[15] D. Mangelinck, K. Hoummada, F. Panciera, M. El Kousseifi, I. Blum, M. Descoins, M. Bertoglio, A. Portavoce, C. Perrin, M. Putero, Progress in the understanding of Ni silicide formation for advanced MOS structures, Phys. Status Solidi -Appl. Mater. Sci. 211 (2014) 152-165. doi:10.1002/pssa.201300167.

[16] D. Mangelinck, Chapter 9 - The Growth of Silicides and Germanides, in: Handb. Solid State Diffus. Vol. 2, Elsevier, 2017: pp. 379-446. doi:10.1016/B978-0-12-804548-0.00009-8.

[17] K. Barmak, K. Coffey, D. Rudman, S. Foner, Phase Formation Sequence for the Reaction of Multilayer Thin-Films of Nb/Al, J. Appl. Phys. 67 (1990) 7313-7322. doi:10.1063/1.344517. 
This manuscript was accepted by J. Appl. Phys. Click here to see the version of record.

[18] E. Emeric, P. Gas, G. Clugnet, C. Bergman, Al-Co reactions in multilayer films: first stages and selective formation of new (metastable) phases, Microelectron. Eng. 50 (2000) 285-290. doi:10.1016/S0167-9317(99)00294-4.

[19] U.R. Evans, The corrosion caused by products of combustion of coal gas, J. Soc. Chem. Ind. 43 (1924) 506-507. doi:10.1002/jctb.5000432003.

[20] B.E. Deal, A.S. Grove, General Relationship for the Thermal Oxidation of Silicon, J. Appl. Phys. 36 (1965) 3770. doi:10.1063/1.1713945.

[21] F. Nemouchi, D. Mangelinck, C. Bergman, P. Gas, U. Smith, Differential scanning calorimetry analysis of the linear parabolic growth of nanometric Ni silicide thin films on a Si substrate, Appl. Phys. Lett. 86 (2005) 041903. doi:10.1063/1.1852727.

[22] C. Cserháti, Z. Balogh, A. Csik, G.A. Langer, Z. Erdélyi, G. Glodán, G.L. Katona, D.L. Beke, I. Zizak, N. Darowski, E. Dudzik, R. Feyerherm, Linear growth kinetics of nanometric silicides in Co/amorphous-Si and Co/CoSi/amorphous-Si thin films, J. Appl. Phys. 104 (2008) 024311. doi:10.1063/1.2957071.

[23] F. Nemouchi, D. Mangelinck, C. Bergman, G. Clugnet, P. Gas, J.L. Lábár, Simultaneous growth of Ni5Ge3 and NiGe by reaction of Ni film with Ge, Appl. Phys. Lett. 89 (2006) 131920. doi:10.1063/1.2358189.

[24] Z. Balogh, M. Ibrahim, A.B. Fuhrich, B. Parditka, R. Schlesiger, P. Stender, Z. Erdelyi, G. Schmitz, Interfacial Reaction and Phase Growth for Various Metal/Amorphous Silicon System, John Wiley \& Sons Inc, Hoboken, 2014.

[25] A.M. Gusak, T.V. Zaporozhets, Y.O. Lyashenko, S.V. Kornienko, M.O. Pasichnyy, A.S. Shirinyan, Diffusion-controlled Solid State Reactions: In Alloys, Thin Films and Nanosystems, Wiley, 2011.

[26] U. Gösele, K.N. Tu, Growth kinetics of planar binary diffusion couples: "Thin-film case" versus "bulk cases", J. Appl. Phys. 53 (1982) 3252-3260. doi:10.1063/1.331028.

[27] S.S.L. M. A. Nicolet, Formation and Characterization of Transition-Metal Silicides, Academic Press, NY, 1983.

[28] F.M. d'Heurle, Nucleation of a new phase from the interaction of two adjacent phases: Some silicides, J. Mater. Res. 3 (1988) 167-195. doi:10.1557/JMR.1988.0167.

[29] C. Lavoie, F.M. d'Heurle, C. Detavernier, C. Cabral, Towards implementation of a nickel silicide process for CMOS technologies, Microelectron. Eng. 70 (2003) 144-157. doi:10.1016/S01679317(03)00380-0.

[30] D. Mangelinck, J.Y. Dai, J.S. Pan, S.K. Lahiri, Enhancement of thermal stability of NiSi films on (100)Si and (111)Si by Pt addition, Appl. Phys. Lett. 75 (1999) 1736-1738. doi:10.1063/1.124803.

[31] D. Deduytsche, C. Detavernier, R.L. Van Meirhaeghe, J.L. Jordan-Sweet, C. Lavoie, Formation and morphological stability of NiSi in the presence of W, Ti, and Ta alloying elements, J. Appl. Phys. 101 (2007) 044508. doi:10.1063/1.2433133. 
This manuscript was accepted by J. Appl. Phys. Click here to see the version of record.

[32] C. Lavoie, C. Detavernier, C. Cabral, F.M. d'Heurle, A.J. Kellock, J. Jordan-Sweet, J.M.E. Harper, Effects of additive elements on the phase formation and morphological stability of nickel monosilicide films, Microelectron. Eng. 83 (2006) 2042-2054. doi:10.1016/j.mee.2006.09.006.

[33] D. Mangelinck, J.Y. Dai, S.K. Lahiri, C.S. Ho, T. Osipowicz, Formation and Stability of NI(PT) Silicide on (100)SI and (111)SI, MRS Online Proc. Libr. Arch. 564 (1999). doi:10.1557/PROC564-163.

[34] K. Hoummada, E. Cadel, D. Mangelinck, C. Perrin-Pellegrino, D. Blavette, B. Deconihout, First stages of the formation of $\mathrm{Ni}$ silicide by atom probe tomography, Appl. Phys. Lett. 89 (2006) 181905. doi:10.1063/1.2370501.

[35] J. Demeulemeester, D. Smeets, C.M. Comrie, N.P. Barradas, A. Vieira, C. Van Bockstael, C. Detavernier, K. Temst, A. Vantomme, On the growth kinetics of $\mathrm{Ni}(\mathrm{Pt})$ silicide thin films, J. Appl. Phys. 113 (2013) 163504. doi:10.1063/1.4802738.

[36] D. Deduytsche, C. Detavernier, R.L. Van Meirhaeghe, C. Lavoie, High-temperature degradation of NiSi films: Agglomeration versus NiSi[sub 2] nucleation, J. Appl. Phys. 98 (2005) 033526. doi:10.1063/1.2005380.

[37] D. Deduytsche, C. Detavernier, R.L. Van Meirhaeghe, J.L. Jordan-Sweet, C. Lavoie, Formation and morphological stability of $\mathrm{NiSi}$ in the presence of $\mathrm{W}, \mathrm{Ti}$, and Ta alloying elements, J. Appl. Phys. 101 (2007) 044508. doi:10.1063/1.2433133.

[38] R.N. Wang, J.Y. Feng, Comparison of the thermal stabilities of NiSi films in Ni/Si, Ni/Pd/Si and Ni/Pt/Si systems, J. Phys. Condens. Matter. 15 (2003) 1935. doi:10.1088/0953-8984/15/12/310.

[39] W. Huang, L. Zhang, Y. Gao, H. Jin, Effect of a thin W, Pt, Mo, and Zr interlayer on the thermal stability and electrical characteristics of NiSi, Microelectron. Eng. 84 (2007) 678-683. doi:10.1016/j.mee.2006.11.006.

[40] X. Yue, L. Zhang, Y. Gao, H. Jin, A Hafnium interlayer method to improve the thermal stability of NiSi film, Microelectron. Eng. 85 (2008) 1723-1727. doi:10.1016/j.mee.2008.04.026.

[41] B. Zhang, C. Hou, Y. Ping, W. Yu, Z. Xue, X. Wei, Z. Di, M. Zhang, X. Wang, Q. Zhao, Impact of an ultra-thin Ti interlayer on the formation of NiSiGe/SiGe, Microelectron. Eng. 137 (2015) 9295. doi:10.1016/j.mee.2014.12.016.

[42] V. Teodorescu, L. Nistor, H. Bender, A. Steegen, A. Lauwers, K. Maex, J. Van Landuyt, In situ transmission electron microscopy study of $\mathrm{Ni}$ silicide phases formed on (001) Si active lines, J. Appl. Phys. 90 (2001) 167-174. doi:10.1063/1.1378812.

[43] A. Noya, M.B. Takeyama, Low-Temperature Formation of NiSi2 Phase in Ni/Si System, Electron. Commun. Jpn. 99 (2016) 85-91. doi:10.1002/ecj.11860.

[44] T. Barge, P. Gas, F.M. d'Heurle, Analysis of the diffusion controlled growth of cobalt silicides in bulk and thin film couples, J. Mater. Res. 10 (1995) 1134-1145. doi:10.1557/JMR.1995.1134.

[45] O. Cojocaru-Mirédin, D. Mangelinck, K. Hoummada, E. Cadel, D. Blavette, B. Deconihout, C. Perrin-Pellegrino, Snowplow effect and reactive diffusion in the Pt doped Ni-Si system, Scr. Mater. 57 (2007) 373-376. doi:10.1016/j.scriptamat.2007.05.007.

[46] D. Mangelinck, K. Hoummada, A. Portavoce, C. Perrin, R. Daineche, M. Descoins, D.J. Larson, P.H. Clifton, Three-dimensional composition mapping of NiSi phase distribution and Pt diffusion 
via grain boundaries in Ni2Si, Scr. Mater. 62 (2010) 568-571.

doi:10.1016/j.scriptamat.2009.12.044.

[47] M. El Kousseifi, K. Hoummada, T. Epicier, D. Mangelinck, Direct observation of NiSi lateral growth at the epitaxial $\theta-\mathrm{Ni2Si} / \mathrm{Si}(100)$ interface, Acta Mater. 99 (2015) 1-6. doi:10.1016/j.actamat.2015.07.062.

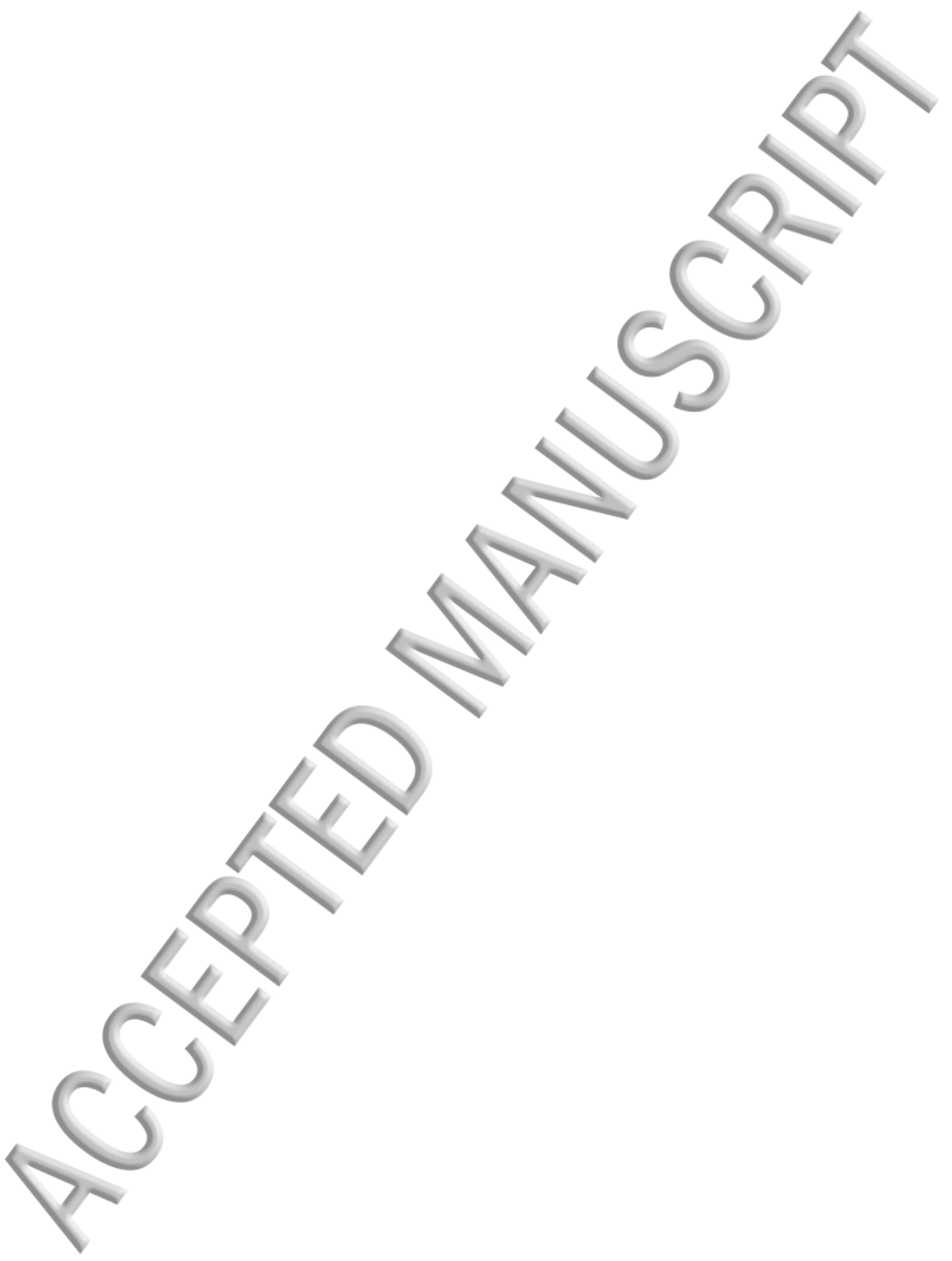


Figure 1 : in situ XRD measurement at $270^{\circ} \mathrm{C}$ for (a) $50 \mathrm{~nm} \mathrm{Ni}$, (b) $50 \mathrm{~nm} \mathrm{Ni} / 0.5 \mathrm{~nm} \mathrm{~W}$, (c) $50 \mathrm{~nm} \mathrm{Ni} / 1$ $n m \mathrm{~W}$, and (d) Ni(5\%)Pt films on Si(100).

Figure 2 : Kinetics of $\delta-\mathrm{Ni}_{2} \mathrm{Si}$ growth for the different samples (a) thickness as a function of time (b) $\log$ (thickness) as a function of log(time) : only the part corresponding to the growth of $\delta-\mathrm{Ni}_{2} \mathrm{Si}$ is shown and the linear (green line) and parabolic (yellow line) behavior are indicated at the origin to interpret the kinetics law. Note that the decrease in the $\delta-\mathrm{Ni}_{2} \mathrm{Si}$ thickness observed in (a) is due to the consumption of $\delta-\mathrm{Ni}_{2} \mathrm{Si}$ by $\mathrm{NiSi}$.

Figure 3: Scheme of the growth of the $\delta$ phase in the presence of a barrier layer, $\beta$,

Figure 4: (a) Variation of the thickness with time in the presence of a barrier of fixed composition and fixed thickness for different barrier thicknesses and for a permeability equal to $0.01 \mathrm{~nm}^{2} / \mathrm{s}$ ) (b) Linear factor, $\mathrm{K},(\mathrm{Eq} . \mathrm{8})$ as a function of the barrier thickness. The following parameters were taken : $\left(\mu_{1}-\mu_{3}\right) / R T=15, \omega^{\delta}=\omega^{\beta}=0.01 \mathrm{~nm} /$ at.,$c_{A}^{\delta}=2 / 3$, and $D_{A}^{\delta}=1 \mathrm{~nm}^{2} / \mathrm{s}$.

Figure 5: Kinetics of formation with a barrier resulting from an alloy (a) Variation of the thickness with time for different barrier permeability (b) Effective coefficient of diffusion as a function of atomic fraction of $C$ in the alloy for a barrier permeability equal to $10^{-2} \mathrm{~nm}^{2} / \mathrm{s}$ ). The following parameters were taken : $\left(\mu_{1}-\mu_{3}\right) / R T=15, \omega^{\delta}=\omega^{\beta}=0.01 \mathrm{~nm}^{3} /$ at.,$c_{A}^{\delta}=2 / 3$, and $D_{A}^{\delta}=1 \frac{n m^{2}}{s}$.

Figure 6: Comparison between experience and simulation for (a) $50 \mathrm{~nm} \mathrm{Ni}$, (b) $50 \mathrm{~nm} \mathrm{Ni} / 0.5 \mathrm{~nm} \mathrm{~W}$, (c) $50 \mathrm{~nm} \mathrm{Ni} / 1 \mathrm{~nm} \mathrm{~W}$, and (d) $\mathrm{Ni}(5 \%) \mathrm{Pt}$ films on $\mathrm{Si}(100)$. The following parameters were taken : $\left(\mu_{1}-\mu_{3}\right) / R T=15, \omega^{\delta}=\omega^{\beta}=0.01 \mathrm{~nm}^{3} /$ at.,$c_{A}^{\delta}=2 / 3$, and $D_{A}^{\delta}=0.04 \mathrm{~nm}^{2} / \mathrm{s}$. The simulation of the $\mathrm{Ni}$ film is also reproduced in (b), (c) and (d) to show the change in kinetics due to the barrier. 

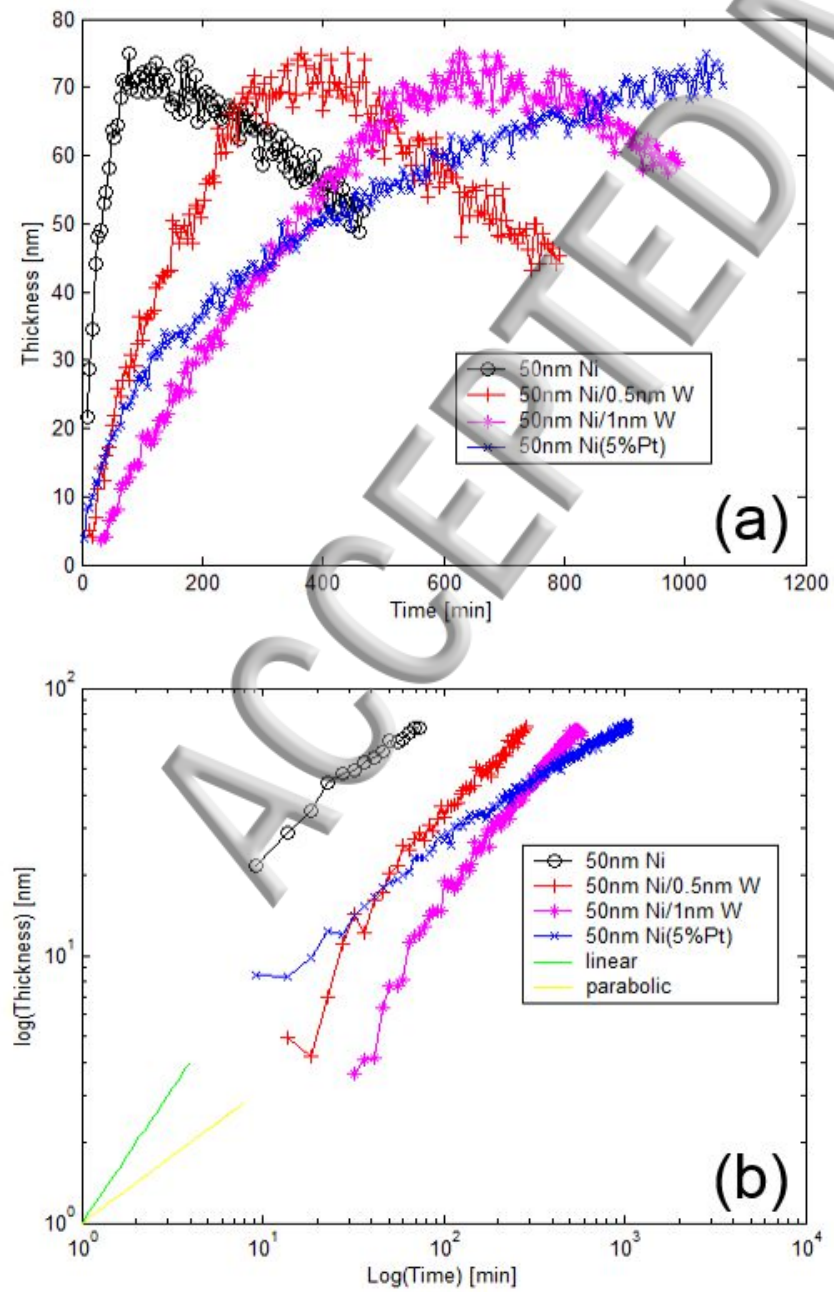


$$
\mu_{1}=\mu_{A}(\alpha / \beta) \quad \mu_{2}=\mu_{A}(\beta / \delta) \quad \mu_{3}=\mu_{A}(\delta / \gamma)
$$

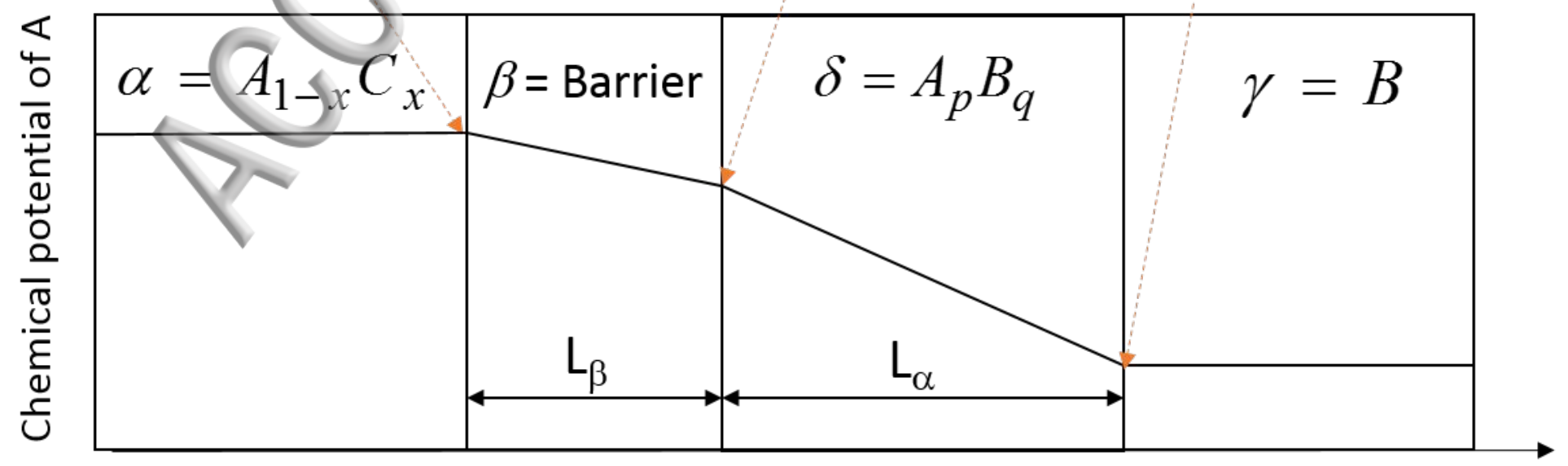

Depth 

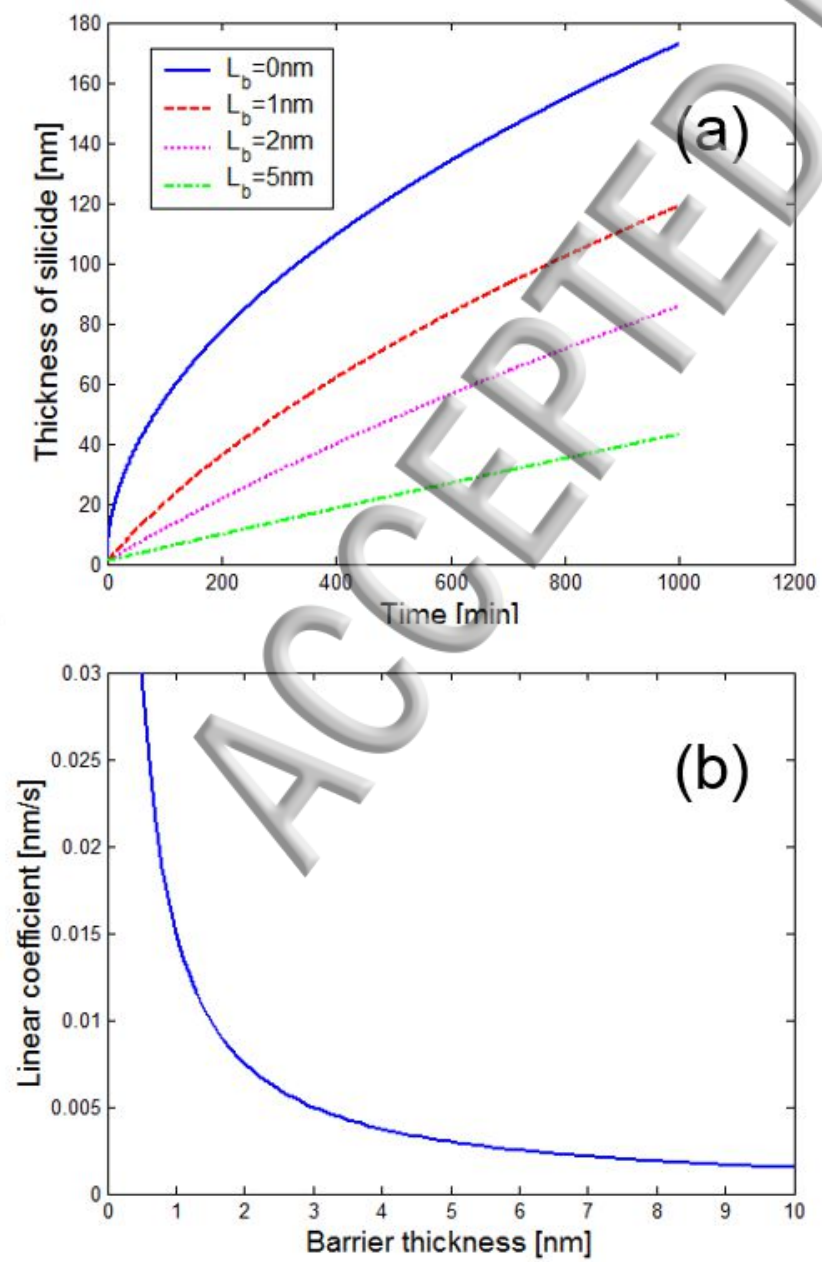


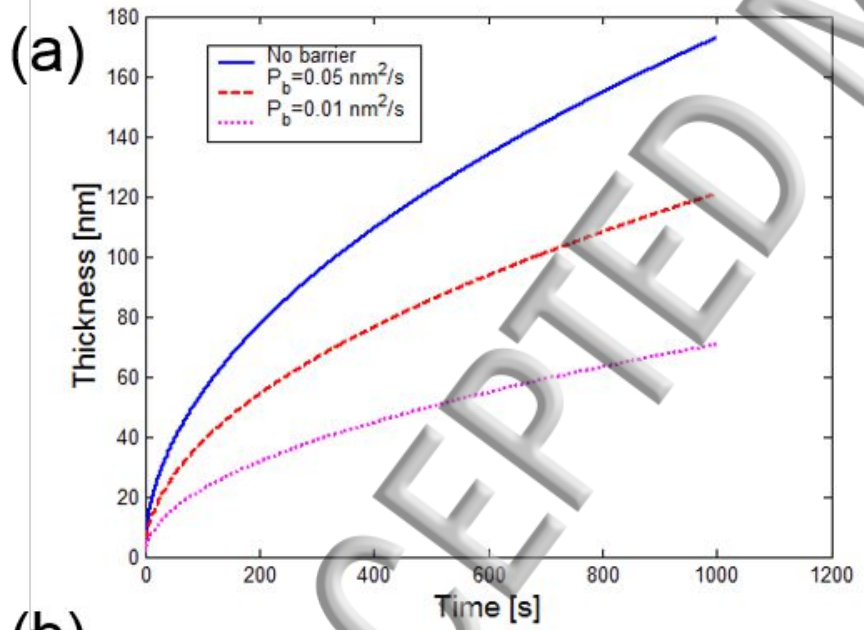

(b)

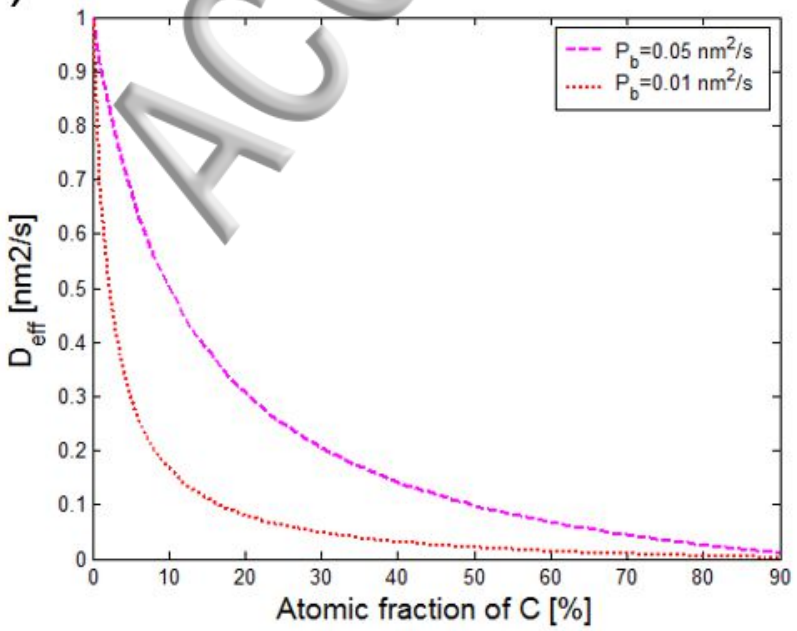


(a)

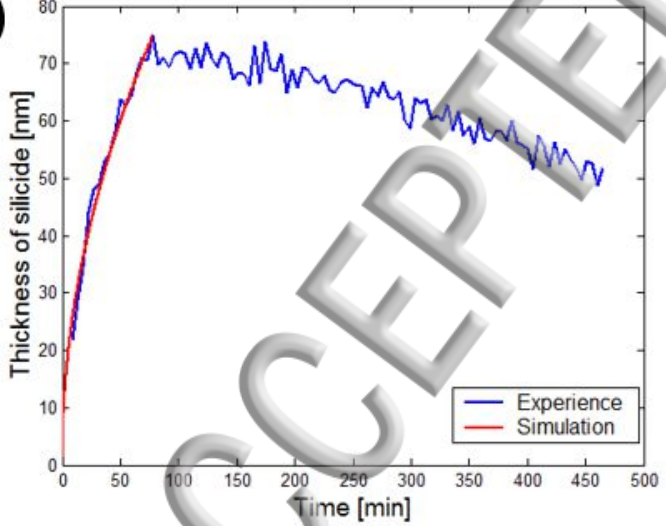

(c)

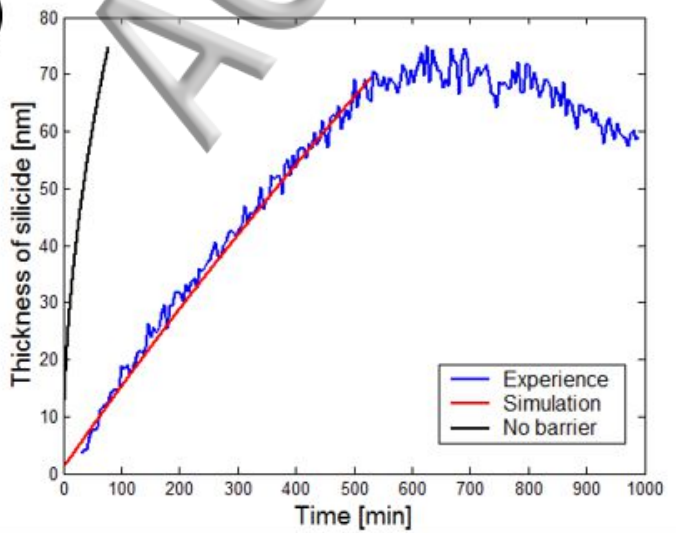

(b)

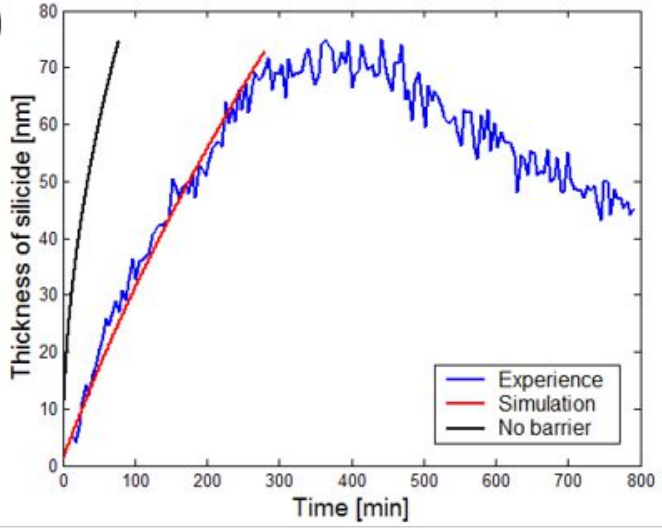

(d)

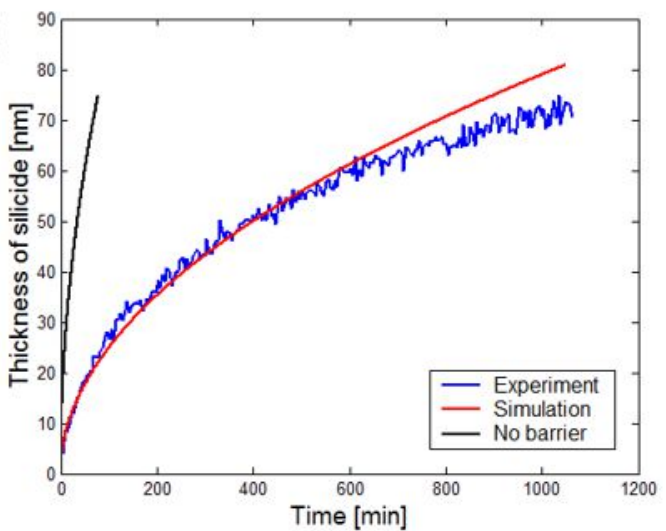

